\title{
DISASTER, PSYCHIATRIC CASUALTIES AND IMPLICATIONS FOR FUTURE WAR
}

\author{
LTC JACOB M ROMO, PhD, MSC \\ MAJ ROBERT J SCHNEIDER, PhD, MSC \\ Department of Military Psychiatry \\ Division of Neuropsychiatry, WRAIR, Washington
}

\begin{abstract}
SUMMARY: The purpose of this paper is to integrate what we know of psychiatric responses to disasters with our projection of the parameters of a tactical nuclear war involving US forces in Europe. In such a scenario there is a high probability that the magnitude of neuropsychiatric (NP) casualties will be greater than ever before experienced, and that current treatment doctrine may not be appropriate or adequate. We conclude by presenting a strategy for dealing with this set of possibilities.
\end{abstract}

\section{Definition of disaster}

Disaster can be defined as the disruption of a socio-cultural system by the impact of extraneous forces. It follows from this definition that it should not matter whether the external force of disruption is a tornado, the stresses of combat, a flood, or indeed a nuclear bomb. The socio-cultural system affected may be a community or a military unit. The seriousness of the disaster is not necessarily a function of the magnitude of the external force but rather the degree and duration of the disruption produced, directly and indirectly. In this paper, we are concerned with psychological dysfunction, or the generation of psychiatric casualties as the direct result of disaster.

\section{Nuclear war: some special problems}

In order to discuss the issue of the generation of psychiatric casualties in a future European theatre war we must first examine the possible nature of that war. Four possible levels of war can be delineated (Douglas, 1976): (1) conventional war, fought intensely and continuously, but with no use of nuclear weapons; (2) a limited theatre nuclear war, fought continuously, but with nuclear (and possibly chemical) devices used against all significant military front-line and rear-area targets; (3) a general theater nuclear war fought with extensive use of nuclear devices throughout the European theater of operations against military targets and civilian populations; and (4) a worldwide thermonuclear holocaust extending to the major civilian population centres and industrial targets of the protagonists. This paper addresses the probabilities inherent in the second level of such a war. The intensity and pitch of battle would be quantitatively and qualitatively greater than were ever faced before.

Stress on such a battlefield may be greater than that in warfare as man has known it in the past, and psychological casualties will increase in number. 
Resupply, personnel replacement and evacuation of dead and wounded may no longer be possible. Tactical nuclear destruction of vital rear supply depots will cause severe shortages of all material necessary not only to wage war, but to ensure soldiers' survival. Most individuals in many units may become physical or psychiatric casualties. Soldiers who survive (or are returned to duty) may not have the benefit of remaining with or returning to their old units and buddies but might find themselves assigned with strangers to units being rapidly reconstituted. In addition, there are other factors affecting NP casualty levels that appear to be of particular significance.

Isolation. Isolation, itself a source of stress, reduces man's capacity for resisting the effects of other stressors. In a nuclear or chemical environment the individual soldier will be more likely to experience isolation as a result of separation from, or disintegration of, his primary group. Loss of contact between his group and higher headquarters is also more likely. Individuals wearing protective clothing in a chemical environment are socially isolated from their fellows due to the difficulty in communicating, including hearing, speaking and even signalling or responding to personal distress.

Ambiguity. Disruption of communications and rapid and frequent changes in the combat situation, in addition to the unknown and ever present danger of radiation or chemical injury, would operate to increase the uncertainty of the soldier about what may be happening to him. It can be expected that the ambiguity normal to combat would be greater on the NBC battlefield with consequent increases in fear and other stress responses,

Conventional war, with episodic fighting and periods for rest and recuperation, including night-time lulls which permit opportunities for attendance to human needs, rest and at least minimal sleep, may not occur. Soviet dotrine states that the offensive " . . will be conducted night and day, in any weather, without let-up until the enemy is defeated." (Sidorenko, 1973). Continuous operations represent an intensification of the stresses to which the soldier is exposed on the battlefield, and an equivalent intensification of the stresses faced by command and support organizations. Resupply of equipment and personnel rapidly expended in continuous operations will carry an additional sense of urgency through all organization levels.

This description of future ground combat hypothesizes a maximization of the factors that historically have led to breakdown in battle - sustained attack, with extensive and continual use of massed indirect fire weapons, including NBC devices. Green troops, as yet untried in combat, will receive their initial battle exposure at levels of intensity and lethality that will be considerably greater than those of World War II or the 1973 Arab-Israeli war. The opening days of war will present large numbers of casualties. Their evacuation, even without NBC devices, will be difficult. Men will be surrounded by the dead and the mutilated. Soldiers in continuous battle will suffer chronic fatigue, have seen their friends wounded and killed, be poorly fed, in need of water, and undoubtedly concerned about the safety of their families and dependants, especially those in Europe. 


\section{Data from past disasters}

We may be able to gain a perspective on these effects by examining the impact of past disasters, or mass casualty situations, in order to make projections about possible psychiatric outcomes. We will discuss historical data from three populations: (1) civilian populations in peacetime disasters; (2) civilian populations in war conditions; and (3) military populations in war.

Civilian populations during peacetime. Almost all persons who directly experience a disaster or who are closely identified with disaster victims suffer some form of acute physiological or emotional stress response, but the evidence suggests that those responses are of relatively short duration and do not usually result in chronic neurotic symptomotology (Fritz, 1954; Janis, 1951). These reactions generally last from a few minutes to a few hours. Most of the evidence suggests that there may be an actual decrease in the incidence of all forms of emotional illness (Fritz, 1961). The low incidence of emotional illness associated with civilian disaster is supported by several types of evidence: (1) there is a general decline in social conflicts including both economic and ethnic distinctions, based on studies of floods, hurricanes and tornadoes; (b) there is often a remission of pre-existing neurotic and psychosomatic symptoms; (c) mass panic is uncommon during disasters either during or immediately following the impact period; (d) there appears to be a reduction of self-aggressive and antisocial behaviour during general disasters: suicide rates decline and looting (in this country) is rare. Each of these points has been well documented in the scientific literature. Civilian disasters do not normally lead to increased psychopathology serious enough to warrant medical attention.

Civilian populations during wartime. Considerable data have been collected from such populations. Generally, the results are similar to those based on peacetime disasters. There is no increase in "pathological mental disturbance" among civilian populations subjected to wartime conditions. Vernon (1941) reported on the effects of air raids in London and found that less than $2 \%$ of those treated in public shelters and admitted to London mental hospitals showed psychological disorders principally related to air raids. Further, among such populations, there are: (a) a decline in social conflicts; (b) a remission in preexisting symptoms; (c) panic is rare; and (d) there is also a decline of antisocial (criminal) behaviour. Similar results have been reported for those German populations subjected to saturation bombing in WW II (Fritz, 1954) and for the Japanese, who suffered not only saturation bombing in 66 cities but atomic attack at Nagasaki and Hiroshima (Janis, 1951).

These points concerning civilian populations and disasters are well documented in the literature. Disasters among civilians do not normally lead to serious or widespread psychiatric breakdown.

Psychiatric casualty rates among soldiers during war. Psychiatric casualty rates are positively correlated with wounded in action (WIA). Beebe and Debakey (1952) reported such correlations in the range of 0.3 to 0.4 . Generally, the ratio of NP casualties to WIA has been 1:5 or fewer in recent wars (Korea and Vietnam). The overall rates did, of course, fluctuate considerably by unit, 
time, type of action, etc, but the proportion returned rapidly to duty has ranged from $50 \%$ in WW II to $85 \%$ in Korea and Vietnam. Although psychiatric casualties constitute a continuing problem to the military, they have constituted only a portion of the casualties, WIA and non-battle disease injury (NBDI), with which the commander has had to deal. This has been true despite the tremendous stress to which troops are exposed.

\section{Breakdown prevented by group cohesion}

The three kinds of populations have all had one factor in common - group cohesion built upon a general system of community or social support. In a civilian population, this would be evidenced by returning to or remaining at the homesite, attempting to rebuild, helping neighbours, giving sustenance to those more gravely affected, and trying to "return to normal." The important point is that individuals generally maintain a relationship to their community, a sense that they belong to and are bonded to both an area and to its people. Despite the extensive damage and high numbers of deaths which have been reported, social support systems have been maintained in the populations we have discussed. This has been accomplished through continued contact with families and friends and the usual influx of great amounts of governmental and other agencies with needed helping personnel and supplies.

In a military population, group cohesion is evidenced by regard for comrades, respect for leaders, concern for their status and that of their friends and leaders, and the urge to contribute to the success of their unit. Such units generally continue to function intact, within an established structure of friendship, work relations, and the expectation that they will continue to carry on. In previous wars, fought by the US, the expectation was held by and of soldiers that when wounded they would ultimately desire and be able to return to their units and comrades when recovered.

It is our contention that group cohesion helps protect individuals from psychiatric problems during times of acute stress, and that this is the factor which has kept psychiatric casualties to a minimum in the studies reported above. To support this contention, let us look at some direct evidence for the importance of cohesion and examine those effects experienced when group cohesion has been lost. Civilian disaster literature has not directly addressed the issues of group cohesion and its corollary, social support. We infer its presence from a variety of sources which report of disaster behaviour. These have been effectively summarized by Fritz (1961) who describes civilian disasters as "therapeutic" to a community. Research demonstrating the importance of social supports for reducing the negative impact of stress has been reported in the medical literature. For example, Nuckolls, Cassell \& Kaplan (1972) found that neither the presence of social support nor social stresses alone predicted pregnancy outcome (normal vs complicated). But those women who had experienced stress in the presence of high social support had dramatically fewer complications (33 vs $90 \%$, respectively). That social supports play an important role in reducing stress related illness has been emphasized by a number of researchers (c.f. Berkman and Syme, 1979; Cobb, 1976). The relation between cohesion and social support 
and response to disaster in military populations is especially germane to this paper and has received considerable attention in the literature. Glass (1958) following examination of WW II and Korean war data, concluded that group cohesiveness and other social factors are equal to intensity and duration of the battle in influencing psychiatric casualty rates. Stouffer, et al., (1949) and Marshall (1951) also repeatedly illustrate the importance of group cohesion in controlling soldiers' behaviour. It is this group cohesion which has enabled the soldier to continue fighting in order to "help his buddies." It concludes the expectation that his unit will continue the fight, that his comrades will look out for him, and that the group is in it together, despite great personal risk. Group cohesion functions not only to prevent breakdown, but has traditionally been part of the treatment process when breakdown has occurred.

We have been able to identify several populations which have experienced disaster where this kind of cohesion did not maintain. For example: (a) Swank (1949) reported that psychiatric casualties become the primary ones and the unit dysfunctional when $75 \%$ of a unit suffered casualties. Because most of these men were lost, at least temporarily, this effectively broke up cohesion and social support; (b) Mullins \& Glass (1973) reported that the 43rd Infantry Div lost almost $10 \%$ of its entire strength as psychiatric casualties in New Georgia. The division has been characterized by poor morale and leadership and a lack of cohesion; (c) Bettleheim (1945), a psychiatrist incarcerated in a WW II concentration camp, wrote extensively of that experience. He reported that when cohesion was lost, allowing certain individuals to withdraw from the group (abandoning social support) such individuals became at highest risk for death; (d) the Israelis reported proportionately few psychiatric casualties in elite airborne troops in the 1973 war, regardless of the intensity of combat. However, they reported a high incidence of psychiatric casualties in those units where the combat situation worked to destroy unit cohesion - for example, in armor units which were dispersed and which suffered high casualties. In addition, married individuals who had endured familial stress (often in the form of loss of supportive significant others) in the past year were at particular risk for becoming a psychiatric casualty (Noy, 1978).

In summary, the literature indicates that despite the large numbers of populations which have suffered diverse forms of disaster, psychiatric casualties are usually relatively small in number or proportion. We attribute this to the existence of rapidly reconstitutable, continuously available group support and cohesion, which minimizes such casualties. We query as to what might happen if cohesion and support is not present or cannot be rapidly reconstituted.

\section{Implications for the future}

The continuous land combat scenario of unceasing attack, use of mass destruction weapons (chemical or nuclear), fast manoeuvre, constant threats to the flank, deep penetration to the enemy rear (threatening communication, combat support, and command and control elements) all are calculated to create a battlefield intolerable to the defender. To protect against nuclear warfare, battle formations will be spread out and widely dispersed. Units will be recon- 
stituted from survivors and will be expected to continue the battle. Many soldiers will have no primary group to which to return. Group cohesion will be lost, and along with this loss the protection from breakdown which it offers to the soldier. We hypothesize that this multiplicity of factors will combine to produce NP casualty rates considerably higher than those seen in the past wars.

Based upon military experience with disaster victims a doctrine containing recommendations for the treatment of NP casualties on the battlefield has been developed. This doctrine is based on the principles of proximity, immediacy, expectancy, simplicity and centrality. These mean that the soldier should be treated in the area of military operations, near the social support of his unit, as quickly as possible, with the expectancy that he will return to his unit. Therapy should be simple and the decision to evacuate rests with one central authority. Utilizing the social support of a cohesive unit is considered an important aspect of the treatment.

This doctrine has not been explicitly espoused for the treatment of civilian disaster victims. Functionally, however, it has been followed. Supplies and assistance immediately flow into the impact area, survivors typically assist other victims, and government efforts are directed at total rebuilding of the affected community.

In the scientific literature we have discussed, the victim has been able to return to the social support of a cohesive group comprised of family, friends, or work associates. Military doctrine specifically presumes that the "disrupted" individual is returned to the support of an intact group. In the war scenario we have described, this doctrine will no longer be applicable, although certain of its tenets will remain useful.

The difficulty of movement across contaminated battlefields, coupled with the tactical dispersion necessary for NBC war will lead to great difficulty in getting mental health professionals to the affected soldier. Proximate treatment may be possible, but the principle of immediacy will not be fulfilled with presently assigned mental health personnel. In addition, the present capability for treatment assumes a much lower rate of NP casualties than we predict. We believe that to ensure the availability of treatment personnel where they are needed requires the training of cadre at all levels in the recognition and treatment of the NP casualty. These cadre could be augmented by the assignment of additional behavioural science specialists to manoeuvre battalions to ensure both proximate and immediate treatment.

The principle of expectancy will probably not be relevant. Individuals will likely be returned to duty with units which have been reconstituted from survivors of several units. The social support of a cohesive unit and "old buddies" is unlikely to be available. The consequences of this for treatment and prognosis might be profound. One solution to this problem could be to train both leaders and cadre in methods designed quickly to create and foster unit cohesion and the development of group solidarity and social support, drawing upon principles of social psychology and organizational effectiveness.

The use of such cadre as the primary agents for both NP treatment and the integrative socialization of men into new groups at the small unit level might be one aspect of this solution. Further, preventive psychiatry programs 
might be designed to help individuals cope when cohesion and group support are not available to counter the effects of randomly reconstituted groups.

The treatment principle of simplicity would still be relevant, perhaps even more so than in the past. Centrality, referring to the decision-making leading to evacuation, will probably be irrelevant. Since rear areas will be destroyed, and transportation difficult, little evacuation will probably be possible.

We believe that the scenario for a possible future tactical nuclear war will lead to the development of proportionately greater numbers of NP casualties than seen in the past. We hypothesize that current doctrine for the treatment of such casualties is not adequate and suggest changes in that doctrine which should be implemented today to avert disaster on the battlefield tomorrow.

\section{REFERENCES}

Beebe G W, Debaky M E. Battle Casualties. Springfield Illinois: Thomas, 1952.

BetTleheim B. Individual and mass behavior in extreme situations. Journal of Abnormal and Social Psychology, 1945. 38: 417-452.

Berkman L F, Syme S L. Social networks, host resistance, and mortality: A nine year follow-up of Alameda County residents. American Journal of Epidemiology, 1979. 109: 186-204.

Coвb S. Social support as a moderator of life stress. Psychosomatic Medicine, 1976. 38: 300-314.

Douglas J D, Jr. The Soviet Theater Nuclear Offensive. Washington, DC: US Government Printing Office, 1976.

Fritz G E. Disaster. In R K Merton and R A Nisbet (Ed) Contemporary Social Problems. New York: Harcourt, 1961.

FrITZ C E, MARKS E S. The NORC studies of human behaviour in disaster. Journal of Social Issues, 1954. 10: 26-41.

Glass A J. Observations upon the epidemiology of mental illness in troops during warfare. In Symposium on Preventive \& Social Psychiatry, Washington: Government Printing Office, 185-198, 1958.

JANIS I L. Air war and emotional stress. New York: McGraw-Hill, 1951.

Marshall S L A. Men Against Fire. Washington: Combat Forces Press, 1951.

Mullins W S, GLASS A J. Neuropsychiatry in WW II: Overseas Theaters, Vol II. Washington, DC: Office of the Surgeon General, 1973.

Noy S. Stress and personality as factors in the causality and prognosis of combat reactions. Paper presented at the Second International Conference on Psychological Stress and Adjustment in Times of War and Peace. Jerusalem, Israel, July 1978.

Nuckolls K B, Cassel J, Caplan B H. Psychosocial assets, life crisis, and the prognosis of pregnancy. American Journal of Epidemiology, 1972. 95: 431-441.

Sidorenko A A. The Offensive: A Soviet View Moscow: Military Publishing House, 1970 (translated for the US Air Force, Washington: US Government Printing Office, 1973).

Stouffer S A, Suchman E A, DeVinney L C, Star S A, William R M. Attitudes Toward Leadership and Social Control. Princeton, New Jersey: Princeton University Press, 1949.

Swank R L. Combat exhaustion. Journal of Nervous and Mental Disease, 1949. 109: 475-508.

VERNo P E. Psychological effects or air-raids. Journal of Abnormal and Social Psychology. 1941; 36: 467-476. 